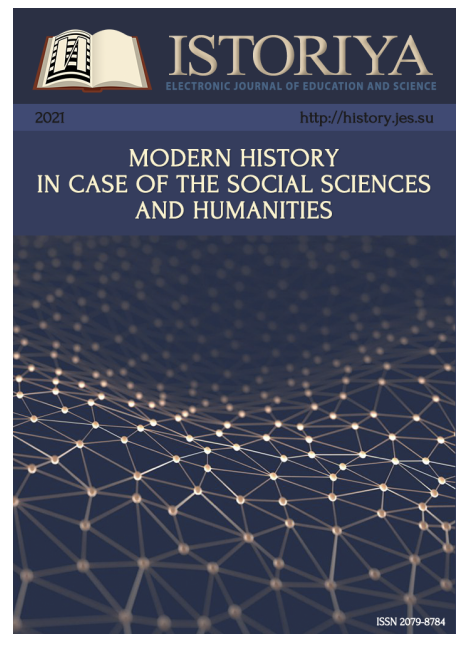

Электронный научно-образовательный журнал «История». 2013-2023

ISSN 2079-8784

URL - $\underline{\text { http://history.jes.su }}$

Все права защищены

Modern History in Case of the Social Sciences and Humanities Tom . 2021

\title{
Sustainable Overall Social Transformation as a Path to Progress
}

\section{Мартынов Аркадий Владленович}

Institute of Economics RAS; International Research Institute for Advanced Systems Russian Federation, Moscow

\section{Аннотация}

The discussion article is concerned with the fundamental issues of future sustainable progress. Assuming the real world challenges, it seems appropriate to turn to the universal concept of systemic stability, the property of which is inherent in one way or another to all social practices, and not only to those reflecting the interaction between society and the environment. In accordance with this concept, the realistic design of institutional changes in conjunction with the resource and organizational-behavioral changes required for sustainable development is intended to occur in the mainstream of a systemic general social transformation. As follows from the above argumentation, the transition to a sustainable general social transformation is real in the case of a synergistic implementation of achievable fundamental shifts.

Ключевые слова: steady progress, social systemic transformation, institutions, technological, demographic and climatic changes

Дата публикации: 25.06.2021

\section{Источник финансирования:}

This article is a translation of: Мартынов А. Устойчивый прогресс как результат общесоциальной системной трансформации // Общество и экономика. 2021. Вып. 1. C. $100-120$. DOI: $10.31857 / \mathrm{S} 020736760013405-4$ 
Мартынов А. B. Sustainable Overall Social Transformation as a Path to Progress // Электронный научно-образовательный журнал «История». - 2021. - Modern History in Case of the Social Sciences and Humanities.

URL: https://history.jes.su/s207987840015615-5-1/. DOI: 10.18254/S207987840015615-5

1 The current global critical situation caused by the deadly epidemic of the coronavirus cannot be ignored when addressing the problem of fundamental social progress. It has proved to be associated with the onset of a prolonged economic recession, established as a result of the stabilization measures taken, especially the reduction in interest rates. The non-economic consequences of the epidemic, manifested in the deactivation of all spheres of social life in most countries, are even more significant.

2 Undoubtedly, after the termination of the acute phase of the present world crisis, the need for an interrelated solution of the enlarged complex of social problems will intensify even more. The achievement of economic and financial stabilization is intended to be accompanied by a radical improvement in the state of social sectors in almost all countries through effective and inevitably huge investments. It should be noted, that health care in not the only one sector, requiring them.

3 It has long been proven that economic growth alone is insufficient for resolving interrelated social problems, which can be coupled with increased social inequality and anti-democratic changes. Truly general social progress due to an equal degree of economic (market) and non-economic drivers, mutually complementary to each other, is needed. This is the opinion widely recognized at the international level, in practical terms, expressed in the comprehensive integration of various indicators of the development progress of modern countries $[1,2]$.

4 The interrelated solution of extremely significant problems, including environmental and climatic ones, to achieve general social progress is possible only on the basis of an integrative approach. Ultimately, based on the universally recognized imperative to ensure the secure existence of our planet.

5 Based on the reformist opinion (for example, [3]), the overall sustainable progress of the society is the immanent feature of its desired development. It is characterized by economic, political, status, ecological, climatic and other quantitative and qualitative parameters, which are assumed to be sustainable in accordance with accepted ideas in the course of the development of society. First of all, it is characterized by the well-known imperatives of sustainable development (SD), presented in the UNapproved integrative framework concept of Agenda 2030 or simply the Agenda [4]. The achievement of these imperatives requires consideration of the entire range of processes of economic and other social changes associated with fundamental, long-term, structural shifts $[5,6]$.

6 A brief review of the existing research groundwork directly related to the topic of the work. Until now, most researchers have relied on the textbook model of the "three cushions" of sustainability - ecological, economic and social, which is presented in detail in an innumerable number of publications, including recent ones (for example, [7]). Undoubtedly, this conceptual model served as the basis for fruitful specific research 
in certain areas of SD and their synthesis. However, it seems insufficient in the light of modern global challenges, when the need for knowingly complex research has arisen.

7 To a certain extent, the theoretical model of social stability acts as an alternative [8-10]. The essence of this model is to substantiate social sustainability as a driver of environmental and economic sustainability. Such a holistic methodology is obviously of limited applicability, since the immanent autonomy of many important processes of economic, technological and other changes is not taken in consideration.

8 Research on socio-ecological systems (SES) is closely related to publications in the mainstream of social sustainability. Apparently, the main achievement in this direction was the formation of a framework concept [11-13]. In the expression of Elinor Ostrom [12], it allows building a bridge between biophysical and social scientific research. Moreover, the methodology based on this concept has been used for a long time in the technology of ecological design, at least in the Scandinavian countries [14]. However, the field of application of this methodology seems to be deliberately limited, since in most cases successful operation is possible under favorable external conditions, market (financial) and others.

9 The author shares the theoretical point of view, which coincides with the opinion of the supporters of the idea of universal stability $[15,16]$. The conceptual approach based on it makes it possible to fully cover the interconnected processes of sustainably reproducible changes in society. It is pertinent to note that this approach is consistent with specific integrative studies of sustainable development in its main interrelated areas in the coming era of digitalization, which have recently been carried out $[17-20]$.

10 Without the enormous role of current market changes being compromised, eventually, fundamental shifts are determined by the long-term directions of development of the economy and society as a whole. Consideration of the phenomenon of fundamental shifts in their integral unity in time and space becomes possible on the basis of the transformational paradigm. This assumption is confirmed by recent research $[21,22]$.

11 Sustainable progress in line with general social system transformation: theoretical basis and methodology. Let us turn directly to the concept of social progress. Following a positivist worldview in the spirit of Comte, it means constant, progressive improvements in all spheres of social life. This understanding of progress is incompatible with the well-known utopian ideas about the possibility of achieving an ideal social order, which means "the end of history".

12 To present a realistic picture of general social progress, it is reasonable to turn to the fundamental theory of transformation of social systems [23-26]. Following this theory, neither economic changes nor changes of another social type can be considered in isolation in the context of the study of the transformation of society. Ultimately, its real picture is expressed by systemic social changes, which are simultaneously manifested in the interactions of economic (market) agents, political players and actors in other arenas of social life. 
The transformation of the social system in its traditional (narrow) understanding covers the main fields of social action: economic, political, status and partly cultural, characterized by the presence of a certain institutional structure and resource provision. At the same time, it is necessary to take into account that social changes in institutionally structured fields are inevitably accompanied by largely noninstitutionalized processes of technological, demographic and climatic changes.

14 Thus, social systemic transformation is a result of the interaction of heterogeneous endogenous institutional/resource shifts, as well as diverse exogenous processes, such as the invention of fundamentally new technologies and a change in solar activity cycles.

15 The following fundamental point should not be ignored. Social systemic transformation cannot be imagined without both integral and interrelated phases of resource turnover: production and consumption of resources, on the one hand, distribution and redistribution of resources, including capital and income, on the other. The phenomenon of precisely the transformation of the social system can be understood only if both sides of the coin are taken into account.

16 The interpretation of sustainable general social progress in the mainstream of the process of systemic transformation looks quite understandable. The initial premise of the systemic transformational concept of progress is a permanent change in production, personal and social needs, based on the achievable new resource, institutional and technological capabilities, expected demographic and climatic changes [27]. This kind of realistically feasible needs, in turn, predetermine the future structural / multisectoral vector of the desired output in the economic space, designed to correspond with the desired vector of distribution of its results, as well as the vector of desired long-term shifts in other fields of social action in the process of transformation. They directly act as objective guidelines for the fundamental development of the social macro as an integral system, during which, provided the necessary conditions are provided, transformational transformations can occur along the path of sustainable progress.

17 It should be borne in mind that a hypothetical possibility is to achieve trajectories of a sustainable general social systemic transformation that directly meets the criteria of optimality. In accordance with these criteria, optimal transformation trajectories are selectable, which presuppose the fulfillment of various conditions of systemic stability as deliberately set constraints.

18 Certainly, everyone can see the example of many successful leading companies (including non-profit ones) on the world stage. It convinces of the possibility of achieving optimal results that meet the conditions of systemic stability by the market and social entrepreneurs themselves as a result of their proactive decisions. However, this opportunity is hardly achievable in many economic and social segments. The main reason is the lack of significant motivation on the part of a huge variety of market and social agents to achieve optimal sustainability in the face of high risk and uncertainty due to both diverse institutional imperfections and the manifestation of the force factor and other negative side effects. Moreover, there are significant opportunities for gaining benefits through rent-seeking or opportunistic behavior. 
As a consequence, the head-on application at the macrolevel of optimality criteria for identifying future sustainable trajectories of structural transformations can bring deliberately distorted actual results. It would be reasonable to expect the reproduction of an unacceptable gap in the dynamics of the "profitable" and other sectors. In particular, in the economic field, it is likely to be expressed in the hypertrophied growth of a number of brown sectors to the detriment of social well-being and ecology and contributing to a further deterioration of the climate at the same time.

20 An obvious question arises: how to ensure the institutional and other conditions for making shifts to the optimal boundaries of general social development as a systemic transformation, moreover, in the mainstream of sustainable progress?

21 Apparently, there is no definitive answer to it yet. In accordance with modern scientific concepts, the existing institutional mechanisms, including the mechanisms of market, social and political contracting, are deliberately insufficient to fully harmonize the interests of the main subjects. The same applies to the use of monetary, financial and tax policy instruments, as well as other instruments of economic and social policy.

22 In the current period of world development, a high risk of failures of individual markets, crises of many national economies and, in general, the global financial crisis remains. It holds true for social upheavals, environmental disasters, collapses of political regimes. It can be argued that most national governments are challenged to reduce this risk. The way out of the situation is to purposefully maintain a normal trend, without prolonged recessions, booms and crises, and national development in line with a general social systemic transformation.

23 Apparently, the time has come to move from the practice of stabilization and stimulating solutions in their very heterogeneous areas to consolidated social regulation aimed at ensuring balanced and constantly progressive development of certain countries and reducing the risk of destabilization and regression. This new setting is supported by the current international experience, primarily in the EU.

24 To understand the designated new stage in the development of modern countries, it seems appropriate to use the idea of universal sustainability, moreover, in relation to the systemic transformation of the entire society. Following this approach, a sustainable systemic transformation is an integral attribute of the desired development of society as an all-encompassing social system.

25 Based on the foregoing, it seems quite logical to turn to the universal concept of systemic sustainability, at least in its existing draft version $[15,16]$. In accordance with this concept, the property of sustainable reproduction is inherent to one degree or another in all social practices, and not only in those that mediate the relationship between society and its environment. Thus, it seems reasonable to spread the criteria of sustainability in relation to the transformation of the entire social system and its main subsystems: economic, status, political. In other words, an immanent sign of sustainable development as transformation is the normality / acceptability of the results of fundamental changes, resource and institutional, on the main fields of social action. It should be noted that social development along such a trajectory fully corresponds to the pragmatic ideology of the New Normality, which gained recognition in the post-crisis period of tenths. 
Fundamental foundations of sustainability of general social systemic transformation In operational terms, the conditions of universal stability themselves require identification through quantifiable resource indicators. In our opinion, it is legitimate to formulate two unifying and interdependent conditions of resource sustainability within the entire social system (Fig. 1).

27 The first of these conditions includes sustainably maintained, rational in essence production and consumption of existing basic resources - material and non-material, human and natural ones, primarily based on the recognized targets for sustainable development in accordance with the Agenda. Moreover, in the future, it will most likely become appropriate to incorporate additional targets that predetermine the trajectories of sustainable reproduction and consumption of resources in their expanding composition.

28 The second condition concerns the allocation and distribution of resources. It presupposes a balanced resource structure and the normal distribution of certain types of resources at all levels of the system hierarchy in accordance with existing criteria. With regard to the economic field, the considered condition means the balance of the main resource, material and financial flows along with the normal distribution of capital and labour and, as a consequence, incomes in the sectoral and regional sections. The normalization of internal and external migration flows is also expected.

29

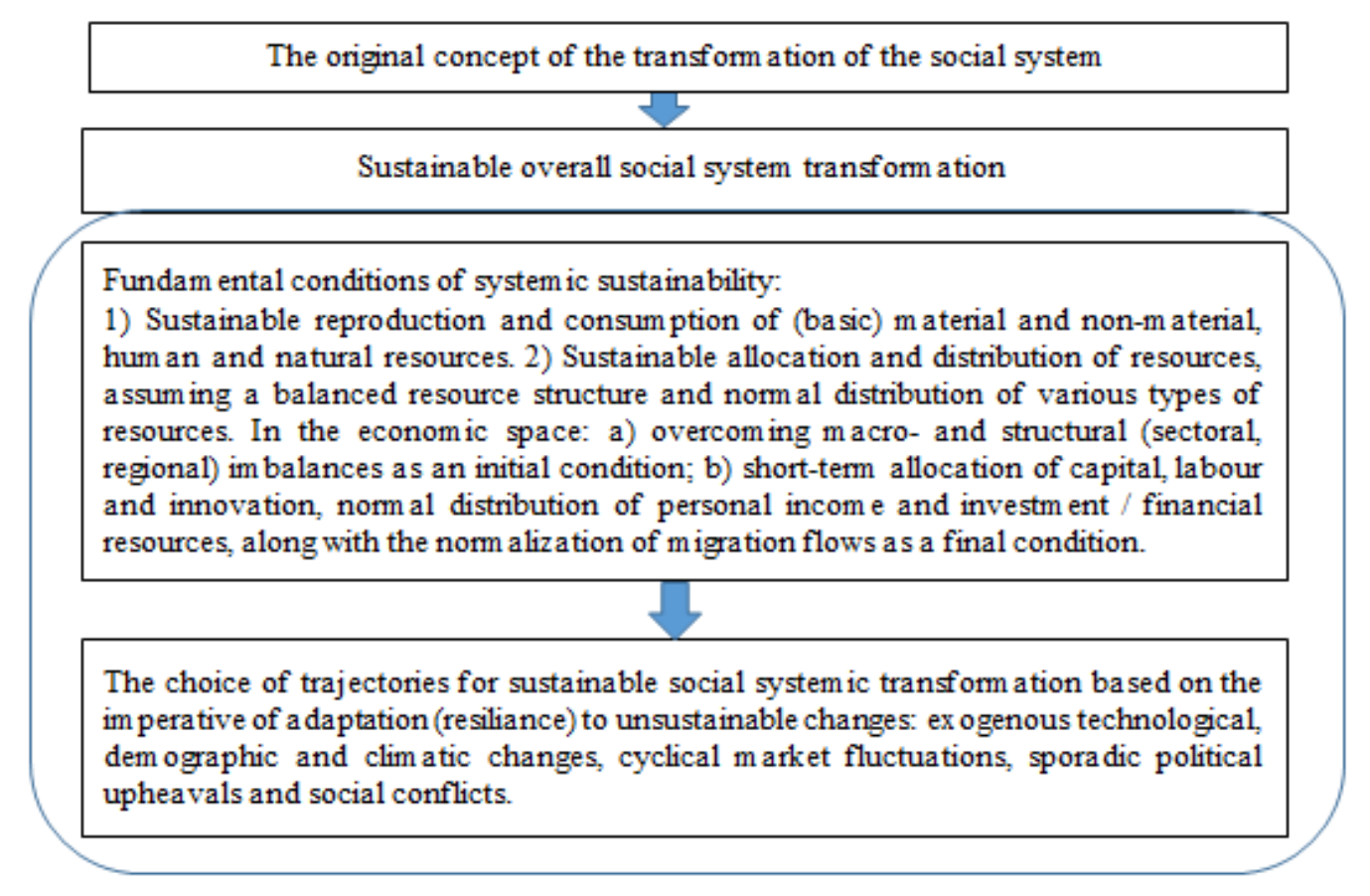

Fig. 1. Sustainable overall social system transformation: a conceptual view

30 It is crucially important that such a transformation is designed to satisfy the imperative of adaptation (resilience) to possible unsustainable changes [28]. First of all, to the expected technological, demographic and climatic changes to the extent that they act as exogenous factors in relation to the transformation of the entire social system and its main components. However, the presence of a huge number of processes of unsustainable and obviously fluctuating changes caused by cyclical market drivers, sporadic political upheavals and diverse social conflicts, can not be ignored. The problem of neutralizing the impact of instability in the future will become central in the 
course of making strategic decisions and implementing mechanisms to neutralize emerging risks [22].

31 The key issue is to ensure resilient adaptation to new technologies in the entire foreseeable future [29, 30]. As evidenced by numerous facts, the use of a number of new technologies, including digital technologies, in principle, does not meet the criterion of economic stability. The shock effect of the development of individual markets where these technologies are being introduced is quite likely. Thus, according to recent highprofile studies [31,32], the consequences of new automation, robotization and the use of technologies based on artificial intelligence will have a very severe impact on labour markets. Human labour will be replaced in many areas of routine activity with an ordinal increase in the number of highly qualified personnel of the new era, distinguished by the intellectual abilities of independent analysis, critical thinking and the ability to informally solve specific problems.

32 The fateful problem of employment in the context of unfolding automation and digitalization is absolutely insoluble only on a market basis. The uncontested imperative lies in the dramatic growth of employment in the social sectors. The number of people employed in a vast range of sectors (education, health care and social work), where there will be a vast territory for the use of technological innovations as social benefits, may increase significantly in the twenties [33]. One can also hope for a significant increase in workers, including intellectuals, in the non-market environmental sector, encompassing many different activities.

33 Based on the formulated criteria conditions of universal sustainability, including resilience, it becomes legitimate to choose further trajectories of general social systemic transformation. Positioning in time and space of institutional and, at the same time, resource transformational shifts, taking into account the influence of external exogenous factors (technological, demographic and climatic changes) and institutional / resource changes on the "adjacent" fields of social action, is of decisive importance. As a result, it becomes possible to reflect adequately the integrative transformation of the entire vector of the state of the social system, based on the imperatives of universal sustainability.

34 At the same time, it makes sense to focus on the following circumstance. The desired transformation of society is not fully limited to the processes of projected sustainable changes. It can include the processes of more progressive changes that are the results of proactive decisions made by purely market agents and social entrepreneurs, provided that overall sustainable development is maintained in the main fields of social action. It would be appropriate to believe that the transformation trajectories of economic and social sectors will increasingly meet recognized criteria in the future due to such decisions. First of all, they are the criteria for improving prosperity / well-being in its broad sense, fully taking into account the state of the human environment, reflected by the indices of life quality and human development, as well as the index of happiness (subjective well-being). Concurrently, following a realistic research position, it is reasonable to judge progress in the course of systemic transformation by the criterion of rationality and efficiency of capital movement (including natural capital) in its various forms, taking into account the relationship between generations [34]. 
Thus, "double-storey" spherical positioning of the process of Sustainable Overall Social Transformation (SOST) seems legitimate. First, it proceeds in the sphere of sustainable development and only then in the sphere of accelerated progressive development. This, in essence, is the substantial idea of ensuring general social progress with its economic and other components on the foundation of a sustainably reproducible transformation.

36 Long-term reproduction of systemic sustainability predetermines the preference for sustainable and smooth long-term trajectories of transformation in the main fields of social action. Their immanent feature lies not with a chaotic impetuous, but in a steadily forward movement towards achievable boundaries, based on the identified opportunities.

37 In the harsh modern realities with regard to the national interests of individual countries, the imperative of sustainability primarily means a guarantee of maintaining an acceptable level and quality of life as well as overall social well-being. This is achievable through the interaction of all social forces, including corporate and other businesses. Thus, it is difficult to question the potentially huge contribution that corporate business can make to achieving sustainability imperatives [35]. This is evidenced by at least a significant positive effect of the initiative of Microsoft, followed by a number of other high-tech giants in the use of green technologies, and at the same time the rejection of the use of "brown" resources. However, the main responsibility in the constant ensuring of the acceptability of the results of national development clearly lies with the state.

38 Finally, it is worth focusing on the following circumstance. The presented conceptual approach proceeds from the need to improve the information base of specific studies of long-term transformations in the main interrelated areas, to which new ones can be added. It objectively acts as a preliminary stage for an exhaustive presentation of the transformation of social systems of various countries in the future through the prism of universal stability.

39 At the same time, it makes sense to focus on the following circumstance. The desired transformation of society is not fully limited to the processes of projected sustainable changes. It can include the processes of more progressive changes that are the results of proactive decisions made by purely market agents and social entrepreneurs, provided that overall sustainable development is maintained in the main fields of social action. It would be appropriate to believe that the transformation trajectories of economic and social sectors will increasingly meet recognized criteria in the future due to such decisions. First of all, they are the criteria for improving prosperity / well-being in its broad sense, fully taking into account the state of the human environment, reflected by the indices of life quality and human development, as well as the index of happiness (subjective well-being). Concurrently, following a realistic research position, it is reasonable to judge progress in the course of systemic transformation by the criterion of rationality and efficiency of capital movement (including natural capital) in its various forms, taking into account the relationship between generations [34].

40 Achievability of the transition to the sustainable transformation of society. The most important prerequisite for the transition to a sustainable overall social 
transformation is technological progress, previously characterized by an absolutely incredible potential of scientific and technical achievements. According to the optimistic forecast for the next decade, the problem of their application in specific economic and social sectors can be successfully resolved thanks to the joint efforts of innovators, ordinary business and, most certainly, the state in collabouration with public organizations. Particularly plausible expectations are reasonably placed on a large-scale and concurrently selective innovation policy, which has been successfully activated in China, Japan and a number of European countries.

41 The result will be a tremendous global spread of new technologies in the coming period called the fourth industrial revolution or the digital revolution. It will translate into global innovation / technological progress, affecting a large number of countries far beyond the industrial world. According to estimates, the prevailing trend of inertial development of the world economy will be reversed in the coming years.

42 Quite understandably, according to the widespread opinion, the digital revolution is seen as an independent driver of sustainable transformation of the entire society [18]. The consequences of this revolution will be expressed in tremendous advances in the field of SD in many types of activities, for example, in urban and rural improvement. Unprecedented technological changes are intended to be supplemented by explicit discrete, time-compressed shifts, interconnected resource and institutional, in the course of general social systemic transformation of various countries. In the near future (that is, after overcoming the global Pandemic), optimists expect a number of grandiose positive metamorphoses in the main regions of the world [27].

43 As follows from the theory of social transformation, the achievement of a sustainable state of a social system presupposes its substantial qualitative change in time and space relative to the initial state. Such a transition is inevitably associated with relative changes in the root institutions of ownership and coordination, the main resource, price and financial proportions, as well as organizational mechanisms in the course of macro-, structural and social reforms. At the same time, these designated system shifts are designed to act as drivers for the implementation of specific SD imperatives in accordance with the Agenda.

44 It would be shortsighted to play down the multifaceted complexity of the Sustainable Overall Social Transformation (SOST) transition. Based on the systemic representation of general social transformation, it is not fully achievable without cardinal changes at the national, as well as at the supranational level.

45 It should be borne in mind: the possibilities of the transition under consideration are highly differentiated for different groups of countries. They are quite prepared in the enclave of advanced countries (such as Switzerland, Norway, Denmark). Here, according to the OECD [36], the achievement of the adopted SD imperatives in most areas actually took place or is likely to occur along with the provision of intra-system balance as well as macro, sectoral and regional ones.

46 Moreover, in a number of other countries, serious prerequisites have emerged for a fairly early implementation of many SD imperatives. Russia is one of such countries [37, 38]. 

(industrial) countries, including post-developing and post-socialist countries, most likely, long and inevitably discrete shifts will be required. The main reason is due to the presence of deep structural gaps in the main market and social sectors, and therefore at the systemic level [39].

48 In the context of the foregoing, the question of the differences between developed market economies (AE) and national economies with emerging markets (EME), which have become established in most post-developing and post-socialist countries with regard to the possibility of approaching a sustainable systemic transformation, is becoming more relevant.

49 The serious flaws in EME are well known in terms of sustainable reproduction criteria. The point at issue is the debt burden in many post-developing countries, an unacceptably sharp increase in income differentiation / inequality of property and a corresponding increase in the contingent of semi-poor undemanding consumers, infrastructural and institutional barriers to the implementation of advanced environmental and social standards [40]. One cannot ignore the continuing market trends in many EMEs to the detriment of the environment and overall social well-being. An eloquent example of this is the incredible scale of "brown" construction in Russia.

50 At the same time, with regard to the development prospects in the coming decade, it is reasonable to consider the significant competitive advantages of EME in the form of relatively lower costs, including wages, and a relatively higher return on investment [41]. Based on the analysis of actual trends [42, 43], the following assumption can be made: in the event of global stabilization after the recession of Covid-19, in a very near future, both conglomerates of countries will converge in terms of the quality of market institutions, infrastructure support and other key parameters of the state of national economic systems. Then it will be feasible to bridge the gap between $\mathrm{AE}$ and $\mathrm{EME}$ in the degree to which the imperatives of sustainable development are met. However, this opportunity is critically dependent on the political course adopted by the countries with emerging markets.

51 Much more pessimistic is the prospect of the desired transition for most developing countries. Their position is characterized by deep flaws, especially in the social sectors. [36] It is unlikely that they will be overcome in 10 years. Moreover, the targets corresponding to the Agenda will not be achieved; the desired result in the period of the twenties is a dramatic reduction in the gap from these boundaries, and only in the next decade, apparently, the question of the transition to a sustainable overall social transformation will arise.

52 Proceeding from the systemic view of the general social transformation, in any country the approval of SOST is fully realistic only if supranational economic, geopolitical and status transformations take place in accordance with the conditions of sustainability. The sustainably maintained economic order should be established as dominant at the global, multi-regional and national levels. It presupposes an unimpeded sustainable trade regime, as well as sustainable regimes of international movement of capital in its various forms and labour, operating based on coordinated application of global, regional and national legislation. 
It can be assumed that on the world stage, at least three groups of countries will be comparable in terms of market potential: 1) the United States, Britain and other countries with a predominantly capitalist institutional structure preserved; 2) China, India, Russia, Indonesia and a number of other non-Western countries; 3) the countries of continental Europe, as well as Japan and Canada. Along with this, the role of regional economic unions, which includes other countries, will remain highly significant.

$54 \quad$ At the same time, achieving a sustainable global political order is equally important. It assumes that the factor of military / state potential will cease to play a dominant role in the global balance of forces as a result of the proliferation of effective preventive weapons (thermonuclear hypersonic, neutron, etc.) in most countries. Monohegemony, like a superpower duopoly (the United States and its closest allies, on the one hand, and China and Russia, on the other), will irrevocably become a thing of the past. The desired stability in the geopolitical space will be ensured through the creation of special institutional and organizational mechanisms and the unconditional application of the international legal regime [44].

55 Achieving sustainable transformation in the geopolitical space in the coming era of digitalization is likely to manifest itself in a long-predicted shift. The political elite will be largely replenished by top management in the innovation and high-tech sectors, as well as in the sectors of the green economy.

$56 \quad$ Maintaining a sustainable status order at the national and supranational levels is of great importance, although still underestimated. Its integrative criterion condition, following the recognized concepts, is the fair distribution of welfare in its broad sense (including the consumption of natural and cultural goods, education) between all generations of fellow citizens with a constant improvement in the quality of their life and the achievement of a reliable social balance.

57 Sustainable transformation of this kind is intended to be associated with constant positive improvements in the status structure, primarily with a steady strengthening of the positions of the middle class and especially the strata of qualified specialists and independent, truly inclusive entrepreneurs. Then, in the case of a parallel formation of a sustainable economic order, there will be a positive renewal of the composition of the highest status groups.

58 By now, apparently, there is a need to develop a practically feasible model of the transition to $808 \mathrm{~T}$ as applied to advanced countries, although this is not fully achievable due to the likely preservation of the extreme weight of external, global and regional, unsustainable processes. The implementation of this model presupposes the achievement of a synergistic complementarity of the ongoing systemic transformational shifts and targeted long-term political decisions.

59 The economic cut of this kind of model, developed on the basis of the most complete information and taking into account sectoral and regional structural shifts, seems to be quite understandable (Fig. 2). The adopted selective targets of sustainable production and consumption of resources are used as the initial setting parameters of the transition framework model. They are complemented by the accepted conditions for the balanced allocation of resources relative to the main factors of output (productive capital, labour and innovation), as well as the conditions for the normal distribution of 
income and capital / financial resources within the entire economic system. These conditions, it is worth clarifying, presuppose the achievement of not only macroeconomic stability, but also sectoral and regional balance.

60

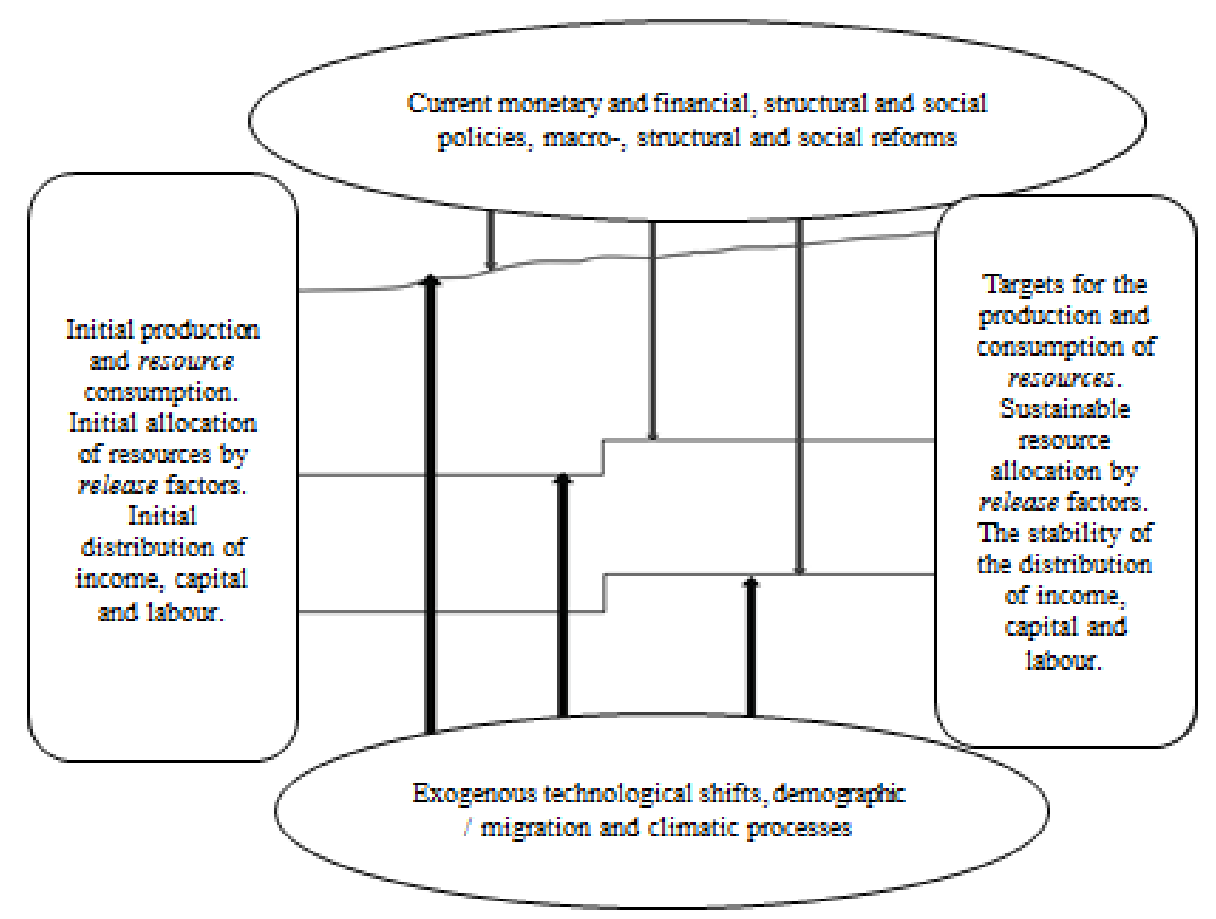

Fig. 2. A contour framework model of a regulated transition to a sustainable overall social transformation

61 The opinion of a number of researchers [45, 46], according to which, for economic sectors, it is legitimate to assume that sustainable output corresponds to the well-known indicator of long-term potential output, seems to be reasonable. With regard to the long-term perspective, it is calculated taking into account real market characteristics (including incomplete resiliency of wages, relative price rigidity, etc.), based on three main conditions. First, the normal loading of production facilities and the use of material resources; achieving a sufficient level of technological innovation and institutional improvement (reflected through the TBR indicator); third, acceptable inflation dynamics and the state of labour markets in terms of employment(for example, $[47,48])$.

62 Macroeconomic and other imbalances can also be taken into account in the process of this kind of modeling [49, 50].

63 Along with this, based on the very meaning of the presented model, sustainable long-term potential output is designed to correspond to the goals and targets of SD. In practical terms, this condition is at least partially fulfilled in the event that the projections of the sectoral output are coordinated with the assumed aggregated indicators of energy intensity and other types of resource intensity directly related to the regulatory imperatives of SD. It should be emphasized that this procedure is productive precisely in the sectorial terms. 
The substantiation of the normal distribution conditions seems to be much more problematic. The legality of the normative setting of the desired levels of the Gini coefficient and other indicators of the distribution of income and capital is highly questionable due to information limitations. On the way to the implementation of such a normative approach, an especially difficult task is to assess reliably the consequences of deepening differentiation of wages ([52]), which will definitely increase in the coming decade of digitalization.

65 A more flexible and pragmatic approach is to determine the ranges of indicators of sustainable distribution of income and capital, based on the impact of these processes on economic output and its main factors $[53,54]$. The main criterion is a consistently positive sign of this influence, assessed on the basis of actually established trends. At the same time, it seems that the final results of these sectoral projections are intended, in the first approximation, to correspond with purely macro forecasts of the distribution (inequality) of income and capital, as well as changes in the social status structure in the respective countries for the long term.

66 However, it should be noted, that the relationship between the output and distribution variables has been poorly studied so far. Only a few recent studies can be noted [55-57]. It is definitely necessary to intensify research efforts in this direction with the participation of teams of international organizations.

67 Also, the integral "input" parameters of the model are vectors of both current stabilization (monetary, financial, etc.) and long-term reform decisions. The latter, in particular, relates to stimulating the development of a green economy through the creation of new jobs.

68 Undoubtedly, political decisions are called upon to proceed exclusively from real possibilities. However, they are largely determined by exogenous technological changes, demographic / migration situation and the influence of climatic factors. Ultimately, the most likely feasible scenarios can be selected among the possible alternatives, following the practice of expert consensus (for example, [58]).

69 Thus, the presented model can be attributed to partly normative and nonoptimization. On its basis, the choice of the scenario of the most probable transition to normal / balanced long-term national development in the future is called upon, based on today's ideas.

70 At the same time, in the process of choosing trajectories for sustainable transformation of individual sectors, the identification of their possible additional growth as a result of the assumed optimal business and consumer decisions in line with recognized theoretical concepts arises. For this purpose, the appeal to behavioral subjective models (agent-based models) looks unambiguously fruitful. Following recent studies $[59,60]$, the use of these models allows one to assess the effect of optimizing the decisions of market and social agents, which is predetermined by a favorable external sustainable environment.

71 The pivotal question concerns the possibility of an integrative study of SD as a transformational process and the implementation of a long-term strategy on this basis. Until now, there is a widespread opinion in wide public circles in favor of the need to 
address the climate threat and other "hot" problems as a matter of priority, and then only to apply the existing arsenal of models and methods to achieve other recognized SD imperatives. In our opinion, the following counterargument is valid: environmental improvement and relative climate stabilization depend on the expected integrative consequences of positive transformational shifts in all areas of social activity. At the same time, the above-mentioned does not call into question the exceptional importance of state policy directly in the field of ecology and climate stabilization, objectively implemented in a relatively autonomous mode.

72 Moreover, the fundamental problem is the alternative of choosing the criteria of sustainability or optimality for assessing the results of overall social transformation. Testing the optimization macrostructural models can yield well-interpreted results with respect to the future allocation of resources and income. However, these optimistic results seem too unreliable, for at least two very compelling reasons. First, the extreme uncertainty of specifying changes over time, both constraints reflecting the conditions of sustainable resource consumption, and existing market and non-economic constraints. Secondly, the actual lack of information to assess the risk of the consequences of violations of the adopted restrictions, taking into account the enormous scale of the deliberately suboptimal activity of economic and other social agents. As follows from our research, a realistic positivist approach is advisable. First, the achievement of sustainable and resiliently adaptive trajectories of transformation. Then, limited optimization of transformation processes in relation to areas where there is a real motivation for market and social entrepreneurs to make rational decisions.

73 A word on the purely theoretical discourse related to the research carried out should be said. The presented theoretical results are definitely not consistent with the well-known concept of institutional evolutionism. Its adherents usually emphasize the broad possibilities of evolutionary adaptation of contractual and other institutional mechanisms to emerging social preferences (for example, [61]). However, unfortunately, one cannot really count on the very approximation of the existing inertial trajectories of institutional changes to the trajectories corresponding to the imperatives of sustainability. To achieve them, there are no alternatives to fundamental changes associated with targeted actions in the field of economic and social policy and long-term institutional and structural reforms. Justification of these changes becomes possible precisely on the basis of the systemic transformation paradigm.

74 It must be admitted that the implementation of strategic plans for progressive sustainable development in the twenties will also run into serious various obstacles sources of risks. Suffice it to just mention the threats of new man-made disasters, previously unexplored epidemics like the coronavirus and ethnic national conflicts. However, if the ideology and practice of sustainable development are approved, these obstacles will be resolved in an acceptable way, without prolonged crises and enormous social damage, on the basis of global, regional and national consensus.

\section{Библиография:}

1. OECD 2015. How's Life?: Measuring Well-being. P.: OECD Publishing, 2015. 
2. Stiglitz J., Fitoussi J.-P., Durand M. Beyond GDP: Measuring What Counts for Economic and Social Performance. P.: OECD Publishing, 2018.

3. Sachs J. The Age of Sustainable Development. N. Y.: Columbia University Press, 2015.

4. Transformation of Our World: The 2030 Agenda for Sustainable Development. Final Document of the UN Summit, adopted on September 25, 2015 [Electronical source]. URL: $\underline{\text { https://sustainabledevelopment.un.org }}$

5. Bobylev S. N., Solovieva S. V. Sustainable Development Goals for the Future of Russia // Problems of Forecasting. 2017. N 3 [Electronical source]. URL: https://cyberleninka.ru/article

6. Bobylev S. and Grigoryev L. In search of the contours of the post-COVID Sustainable Development Goals: The case of BRICS // BRICS Journal of Economics. 2020. № 2 (1). 4-24 [Electronical source]. URL: https://doi.org/10.38050/2712-7508-2020-7

7. Purvis B., Yong M. and Robinson D. Three pillars of sustainability: in search of conceptual origins. Sustainability Science. 2018. № 14 (3). P. 681-695.

8. Boström M. SSPP: A missing pillar? Challenges in theorizing and practicing social sustainability: Introduction to the special issue. Sustainable Science Practice Policy. 2012. 8: 3-16 [Electronical source]. URL: http://search.proquest.com/openview

9. Boyer R., Peterson N., Arora P., Caldwell K. Five approaches to social sustainability and an integrated way forward. Sustainability. 2016 [Electronical source]. URL: https://www.mdpi.com

10. Eizenberg E., Jabareen Y. Social Sustainability: A New Conceptual Framework. Sustainability. 9: 68-85. 2017 [Electronical source]. URL:

https://doi.org/10.3390/su9010068

11. Berkes F., Folke C. Linking Social and Ecological Systems: Management Practices and Social Mechanisms for Building Resilience. N. Y.: Cambridge University Press, 1998.

12. Ostrom E. A diagnostic approach for going beyond panaceas. Proceedings of the National Academy of Sciences of the United States of America 104(39): 15181-15187. 2007 [Electronical source]. URL: https://doi.org/10.1073/pnas.0702288104

13. Partelow S. A review of the social-ecological systems framework: applications, methods, modifications, and challenges. Ecology and Society 23 (4): 36. 2018 [Electronical source]. URL: https://doi.org/10.5751/ES- 10594-230436

14. Schlüter M., Orach K., Lindkvist E. and Martin. R. Toward a methodology for explaining and theorizing about social-ecological phenomena. Current Opinion in Environmental Sustainability. 39: 44-53. August: 2019 [Electronical source]. URL: https://doi.org/10.1016/j.cosust.2019.06.011 
15. Giddings B., Hopwood B. \& O'Brien G. Environment, economy and society: fitting them together into sustainable development. Sustainable Development, 2002. 10: 187196.

16. Fisher J. and Rucki K. Re-conceptualizing the Science of Sustainability: A Dynamical Systems Approach to Understanding the Nexus of Conflict, Development and the Environment. Sustainable development, 2017. 25: 267-275.

17. TWI2050 - the World in 2050. 2018. Transformations to Achieve the Sustainable Development Goals.Laxenburg: International Institute for Applied Systems Analysis.

18. TWI2050 - The World in 2050. 2019. The Digital Revolution and Sustainable Development: Opportunities and Challenges. Laxenburg: International Institute for Applied Systems Analysis.

19. WBGU — German Advisory Council on Global Change. 2019. Towards our Common Digital Future. Summary. Berlin: WBGU.

20. Sachs J., Schmidt-Traub G., Kroll C., Lafortune G. and Fuller G. Sustainable Development Report 2019. N. Y.: Bertelsmann Stiftung and Sustainable Development Solutions Network, 2019.

21. Islam N. and Iversen K. From "Structural Change" to "Transformative Change": Rationale and Implications. DESA Working Paper. No. 155. 2018 [Electronical source]. URL: https://un.org/development/desa/publications/working-paper/wp155

22. Transformation towards sustainable and resilient societies in Asia and in the Pacific. 2018. United Nations, Asian Development Bank, United Nations Development Program [Electronical source]. URL: http://sdgasiapacific.net/download/SDG_Resilience_Report.pdf

23. Polanyi K. The Great Transformation // SPb.: Aletheia, 2002.

24. Parsons T. On social systems. M.: Academic Project, 2002.

25. Giddens E. Organization of society. Essay on the theory of structuration. M.: Academic Project, 2003.

26. Luhmann N. Social systems. SPb.: Science, 2007.

27. Martynov A. On the ideology of future world progress // Society and Economy. 2018. № 11. P. 5-24 [Electronical source]. URL: https://oie.jes.su

28. Gallopin G. Linkages between vulnerability, resilience and adaptive capacity. Global Environmental Change, 2006. 16: 293-303.

29. Global Sustainable Development Report. 2019. United Nations [Electronical source]. URL: https://unstats.un.org $>$ sdgs $>$ The- Sustainable- Development 
30. Körner K., Schattenberg M. and Heymann E. Digital economics. How AI and robotics are changing our work and our lives. Frankfurt am Main. Deutsche Bank Research. 2018 [Electronical source]. URL:

http://dbresearch.com/.../Digital_economics\%3A_How

31. Korinek A., Stiglitz J. E. Artificial Intelligence, Worker-Replacing Technological Change, and Income Distribution. NBER working paper 24174. 2017 [Electronical source]. URL: www.nber.org/papers/w24174

32. Acemoglu D., Restrepo, P. Artificial Intelligence, Automation and Work. NBER Working Paper No. 24196. 2018 [Electronical source]. URL: http:// www.nber.org/papers/w24196

33. Greening with jobs. 2018. World employment and social outlook. Geneva: ILO [Electronical source]. URL: https://ilo.org/wesogreening/documents/WESO_Greening_EN web2.pdf

34. The Inclusive Growth and Development Report. 2017. Geneva: World Economic Forum [Electronical source]. URL: http://www3 .weforum.

org/docs/WEF_Forum_IncGrwth_2017.pdf

35. Sustainable Business Transformation Barometer. Effie Russia. 2019 [Electronical source]. URL: https://home.kpmg/ru/ru/home/insights/2019/10/barometer

36. OECD 2019. Measuring Distance to the SDG Targets 2019: An Assessment of Where OECD Countries Stand, OECD Publishing. Paris [Electronical source]. URL: https://doi.org/10.1787/a8caf3fa-en

37. The UN Sustainable Development Goals and Russia: a report on human development in the Russian Federation. Analytical Center for the Government of the Russian Federation, 2016 [Electronical source]. URL:

http://ac.gov.ru/files/publication/a/11068.pdf

38. Voluntary National Review of the Implementation of the 2030 Agenda for Sustainable Development. Analytical Center for the Government of the Russian Federation, 2020.

39. Global economic prospects. June 2020. Washington, DC: World Bank, 2020. DOI: 10.1596/978-1-4648-1553-9.

40. Global economic prospects. June 2019: Heightened Tensions, Subdued Investment. Washington, DC: World Bank. DOI: 10.1596/978-1-4648-1398-6.

41. Martynov A. V. The future of economies with emerging markets // International Economics, 2020. No. 9. P. 27-34. DOI: 10.33920/vve-04-2009-05.

42. McKinsey Global Institute. 2018. Outperformers: High-growth emerging economies and the companies that propel them [Electronical source]. URL:

http://www.mckinsey.com/mgi. 
43. The Global Competiveness Report 2019. 2019. Geneva, Switzerland. World Economic Forum [Electronical source]. URL: https:/www.weforum.org/gcr

44. Mazarr M. (2018). Summary of the Building a Sustainable International Order Project. RAND Corporation [Electronical source]. URL: https://rand.org/pubs/research_reports/RR2397.html

45. Anvari V., Ehlers N., Steinbach R. A semi-structural approach to estimate South Africa's potential output, South African Reserve Bank. 2014.

46. Shackleton R. Estimating and projecting potential output using CBO's forecasting growth model. Working paper 2018-3. 2018 [Electronical source]. URL:

http://www.cbo.gov/publication/53558

47. Global economic prospects. January 2018: Broad-Based Upturn, but for How Long? Washington, DC: World Bank. DOI:10.1596/978-1-4648-1163-0.

48. Andersson M., Szörfi, B., Tóth, M. andZorellN. Potential output in the post-crisis period. ECB. Economic Bulletin, 7:49-70. 2018 [Electronical source]. URL: http://www.ecb.europa.eu $>$ pub $>$ html $>$ eb201807.en.html

49. Alberola E., Estrada A. and Santabárbara D. Growth and imbalances in Spain: a reassessment of the output gap. Journal of Spanish economic association. 2014.5 (2-3). P. 333 -356. DOI: 10.1007/s 13209-014-0112-z

50. Berger H., Dowling T., Lunan S., Mrkair M., Rabanal D., Sanjani T. Steady as she goes: estimating potential output during financial "Booms and Busts". IMF. Working Paper 15/233. 2015 [Electronical source]. URL:

https://ideas.repec.org/p/imf/imfwpa/15-233.html

51. Coibion O., Gorodnichenko Y. and Ulate M. "The Cyclical Sensitivity in Estimates of Potential Output". Brookings Papers on Economic Activity, Economic Studies Program, The Brookings Institution, 2018. Vol. 49 (2 (Fall)). P. 343-441.

52. Vo D., Nguyen T., Tran N. and Vo A. What Factors Affect Income Inequality and Economic Growth in Middle-Income Countries? Journal of Risk and Financial Management. № 12 (1). 2019 [Electronical source]. URL: https://doi.org/10.3390/jrfm12010040

53. Cingano F. Trends in Income Inequality and its Impact on Economic Growth. OECD Social, Employment and Migration Working Papers. No. 163. OECD Publishing. 2014

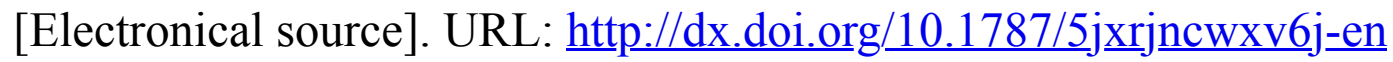

54. Dabla-Norris E., Kochhar K., Ricka F., Suphaphiphat N. and Tsounta E. Causes and Consequences of Income Inequality: A Global Perspective. International Monetary Fund. 2015 [Electronical source]. URL: https://ideas.repec.org/p/imf/imfsdn/15-13.html

55. Bernardo G. and D'Alessandro S. 2016. System-dynamic analysis of employment and inequality impacts of low-carbon investment in Environmental Innovation and 
Societal Transitions. DOI: 10.1016/j. eist .2016 .04 .006

56. Taylor L., Foley D. and Rezai A. An Integrated Approach to Climate Change, Income Distribution, Employment, and Economic Growth. Ecological economics, 2016. 121(C): 196-205.

57. Hardt L. and O'NeillD. Ecological Macroeconomic Models: Assessing Current Developments. Ecological Economics. 2017. 134. P. 198-211 [Electronical source]. URL: http://www.elsevier.com/locate/ecolecon

58. Congress Budget Office. 2019. An Update to the Budget and Economic Outlook: 2019 to 2029. [Electronical source]. URL: http:// www.cbo.gov/publication/55551

59. David H., Gatti D. 2018. Agent-based macroeconomics. Bielefeld working papers in Economics and Management. 2. DOI: 10.4119/unibi/2916999

60. Dosi G., RoventiniA. More is Different ... and Complex! The Case for Agent-Based Macroeconomics. LEM. Working paper series, 2019/01. 2019 [Electronical source]. URL: lemwps/2019-01.html

61. Hodgson G. Conceptualizing Capitalism: Institutions, Evolution, Future. Chicago: University of Chicago Press, 2015. 


\title{
Sustainable Overall Social Transformation as a Path to Progress
}

\author{
Arkady Martynov \\ Institute of Economics RAS; International Research Institute for Advanced Systems \\ Russian Federation, Moscow
}

\begin{abstract}
The discussion article is concerned with the fundamental issues of future sustainable progress. Assuming the real world challenges, it seems appropriate to turn to the universal concept of systemic stability, the property of which is inherent in one way or another to all social practices, and not only to those reflecting the interaction between society and the environment. In accordance with this concept, the realistic design of institutional changes in conjunction with the resource and organizational-behavioral changes required for sustainable development is intended to occur in the mainstream of a systemic general social transformation. As follows from the above argumentation, the transition to a sustainable general social transformation is real in the case of a synergistic implementation of achievable fundamental shifts.
\end{abstract}

Keywords: steady progress, social systemic transformation, institutions, technological, demographic and climatic changes

Publication date: 25.06 .2021

\section{Citation link:}

Martynov A. Sustainable Overall Social Transformation as a Path to Progress // ISTORIYA. - 2021. - Modern History in Case of the Social Sciences and Humanities. URL: https://history.jes.su/s207987840015615-5-1/. DOI: $10.18254 / \mathrm{S} 207987840015615-5$

Код пользователя: 0; Дата выгрузки: 26.04.2023; URL - http:/history.jes.su/s207987840015615-5-1/ Bce права защищены. 